\title{
Refrigerated storage of ram sperm in presence of Trolox and GSH antioxidants: Effect of temperature, extender and storage time
}

\author{
Q1 María Mata-Campuzano,a,b, Manuel Álvarez-Rodrígueza,b,c,d, \\ Julio Tamayo-Canul a,b, Elena López-Urueña $a^{\mathrm{a}, \mathrm{c}}$, Paulino de Paz ${ }_{\wedge}^{\mathrm{a}, \mathrm{b}}$, \\ Luis Anel $\wedge_{\wedge}^{\mathrm{a}, \mathrm{c}}$, Felipe Martínez-Pastor ${ }_{\wedge}^{\mathrm{a}, \mathrm{b}, *, 1}{ }^{\text {, Mercedes Álvarez }} \hat{\wedge}_{\wedge}^{\mathrm{a}, \mathrm{c}, 1}$ \\ a INDEGSAL, University of León, 24071 León, Spain \\ b Department of Molecular Biology, University of León, 24071 León, Spain \\ c Department of Medicine, Surgery and Veterinary Anatomy, University of León, 24071 León, Spain \\ d DEPI, Institute of Technology of Conkal, Conkal, Mexico
}

\section{A R T I C L E I N F O}

\section{Article history:}

Received 1 July 2014

Received in revised form

26 September 2014

Accepted 2 October 2014

Available online $\mathrm{xxx}$

\section{Keywords:}

Ram

Semen

Refrigerated liquid storage

Antioxidant

Extender

\begin{abstract}
A B S T R A C T
Antioxidants have a potential to improve the quality and fertility of refrigerated-stored ram semen. Reduced glutathione (GSH) and Trolox $(0.2,1$ and $5 \mathrm{mM})$ were evaluated in ram semen preserved at 15 and $5^{\circ} \mathrm{C}$ up to 48 and $96 \mathrm{~h}$, respectively. Extenders were also evaluated $\left(15^{\circ} \mathrm{C}\right.$ : Tris-citrate-fructose, TCF, without lipids, and TES-Tris-fructose $10 \%$ egg yolk, TTF-EY; $5^{\circ} \mathrm{C}$ : TTF-EY and 3.5\% soybean lecithin, TTF-SL; INRA96 at both temperatures). Storage at $5^{\circ} \mathrm{C}$ resulted in poorer quality than $15^{\circ} \mathrm{C}$ up to $48 \mathrm{~h}$, while allowing acceptable quality at $96 \mathrm{~h}$. Antioxidants had few effects on sperm quality, with use of Trolox resulting in reduced motility and viability in TCF. Storage at $15^{\circ} \mathrm{C}$ in the TCF extender resulted in decreased motility, viability and mitochondrial activity compared with use of TTF-EY. Sperm quality when storage was at $5^{\circ} \mathrm{C}$ was similar, but storage in TTF-SL resulted in decreased motility and mitochondrial activity. Acrosomal status was only slightly affected by extender and antioxidant. Mitochondrial activity was improved by antioxidants in TTFSL, and GSH at $5 \mathrm{mM}$ when semen was stored at $5^{\circ} \mathrm{C}$ in TTF-EY. A preliminary artificial insemination trial indicated that supplementation with GSH has the potential for improving lambing $(P<0.1)$. In conclusion, use of antioxidants resulted in lesser effects than extender composition or storage time on quality of ram semen. Use of Trolox negatively impacted sperm quality and GSH had some positive impacts. The use of soybean lecithin requires further research to assess its impact on mitochondria.
\end{abstract}

(C) 2014 Published by Elsevier B.V.
* Corresponding author at: INDEGSAL, University of León, 24071 Keón, Spain. Tel.: +34 687365 362; fax: +34 987291282 .

E-mail addresses: felipe.martinez@unileon.es, f.martinez.pastor@gmail.com (F. Martínez-Pastor).

1 Authors contributed equally to this study.

\section{Introduction}

An increasing number of antioxidants has been tested during the last two decades in relation to semen quality. However, with some promising results for adding antioxidants either to the diet (Contri et al., 2011; Speight et al., 2012) or to extenders (Coyan et al., 2011; DomínguezRebolledo et al., 2010; Nasiri et al., 2012; Vallorani et al., 
2010), these substances have not attained widespread use. The reason is the variability of results, with many studies showing little improvement (Foote et al., 2002) or even detrimental effects (Mata-Campuzano et al., 2012a,p) on sperm quality. Most importantly, studies where fertility has been evaluated have not provided positive results (Bucak et al., 2010; Foote et al., 2002; Memon et al., 2012; Tuncer et al., 2010). With these circumstances, the potential benefits do not compensate for the cost of supplementing the diet or extenders with antioxidants.

Nevertheless, there are some situations where the application of antioxidants seems promising in terms of improved sperm quality and fertility (Xia et al., 2012). One of these situations is with the use of liquid semen (refrigerated) for artificial insemination (AI) of sheep. Despite of many technical advances in the last decades, $\mathrm{AI}$ in sheep has not achieved the widespread use that has occurred in the cattle or swine industries. Low economical return, variable fertility rates and more rapid loss of semen quality with storage time are important obstacles for the routine use of these techniques (Anel et al., 2006; Druart et al., 2009; Faigl et al., 2012; Palacín et al., 2012; Salamon and Maxwell, 2000). Lengthening the usable time of the semen doses would allow for increasing the interval from sperm collection to use in AI programs. This could benefit logistics (transport at long distances) while improving the results obtained by vaginal or cervical AI. Whereas it is true that semen cryopreservation offers advantages regarding management and transport of the semen, fertility results in sheep remain unsatisfactory, unless laparoscopic insemination (LAI) is used. This complicates the use of semen in AI programs, and moreover the LAI procedure is currently banned for use in several countries (Faigl et al., 2012).

Reducing the storage temperature from 15 to $5^{\circ} \mathrm{C}$ has allowed for lengthening of semen storage while maintaining viability of sperm cells. However, O'Hara et al. (2010) have shown that storage at $15^{\circ} \mathrm{C}$ was more advantageous than storage at $5^{\circ} \mathrm{C}$ for short times, although storage at $5{ }^{\circ} \mathrm{C}$ yielded greater fertility at $72 \mathrm{~h}$ (blastocyst development after IVF). It is possible that many factors affect the sperm physiology during storage, and this scenario offers an important opportunity to test protective compounds such as antioxidants. With previous research, it has been suggested that adding antioxidants - either enzymatic (Maxwell and Stojanov, 1996) or non-enzymatic (Bucak et al., 2012; Mara et al., 2005) - could benefit the quality and fertility of ram semen after liquid storage at different temperatures. Therefore, a study was previously performed on the effects of the antioxidants Trolox and reduced glutathione (GSH) during cooled storage at $5{ }^{\circ} \mathrm{C}$ and $15^{\circ} \mathrm{C}$. Trolox, an analog of vitamin $\mathrm{E}$, has been successfully tested for controlling lipid peroxidation in ram sperm during cryopreservation (Maia et al., 2010), and thiols have been proved to be excellent radical scavengers and blockers of lipid peroxidation (Deneke, 2000). Indeed, some studies have demonstrated that GSH is very effective in protecting mammalian sperm against oxidative stress (Bilodeau et al., 2001). Both antioxidants were previously evaluated, obtaining promising results, although results depended on the experimental setting (Anel-López et al., 2012; Domínguez-Rebolledo et al., 2010).
In the present study, the effect of extender composition on storage and antioxidant effects was also considered. When reducing the temperature, cold shock can greatly diminish sperm quality. Whereas antioxidants could prevent this effect by scavenging free radicals produced by the events associated with cooling, extender supplements are used to protect sperm membranes (Bergeron and Manjunath, 2006), and could also prevent production of free radicals and even improve the effects of antioxidants (Alvarez-Rodríguez et al., 2013; Pérez-Pé et al., 2001). Thus, for each storage temperature extenders with different composition were evaluated. At $15^{\circ} \mathrm{C}$, a Tris-citric acid-fructose (TCF) extender, typically used for short-term ram semen storage, and a TES-Tris-fructose (TTF) with $10 \%$ egg-yolk (TTF-EY). For the preservation at $5^{\circ} \mathrm{C}$, the TTF extender, supplemented with egg yolk (TTF-EY) or with $3.5 \%$ of soybean lecithin (TTF-SL) was used. Egg yolk is well known to protect sperm membranes during cooling and freezing (Bergeron and Manjunath, 2006), but lecithins could be a suitable option for this purpose also (Watson, 1981), having been proposed as a hygienic and effective alternative to products of animal origin (Emamverdi et al., 2013; Forouzanfar et al., 2010). Indeed, there are available commercial extenders based on soybean lipids that have been successfully used for ram semen chilled storage (Khalifa et al., 2013).

\section{Materials and methods}

\subsection{Reagents and media}

Mitotracker Deep Red, SYBR-14 and YO-PRO-1 iodide were purchased from Invitrogen (Carlsbad, CA, USA). Other chemicals such as propidium iodide (PI), PNA-FITC (peanut agglutinin conjugated with fluorescein isothiocyanate), DMSO and extender components were purchased from Sigma (St. Louis, MO, USA). Stock solutions of fluorescence probes were prepared in DMSO at $1 \mathrm{mM}$, except YO-PRO-1 $(75 \mu \mathrm{M})$, PI $(1 \mathrm{mg} / \mathrm{mL}$ in water $)$ and PNA-FITC $(0.2 \mathrm{mg} / \mathrm{mL}$ in water). These stocks were kept at $-20^{\circ} \mathrm{C}$ and in the dark. Flow cytometry equipment, software and consumables were purchased from Becton Dickinson (San Jose, CA, USA).

\subsection{Experimental design}

Semen was collected, assessed, pooled and placed as different aliquots in tubes to assess the effect of the antioxidants GSH and Trolox at 0.2, 1 and $5 \mathrm{mM}$ concentrations in refrigerated storage at two temperatures using different extenders as depicted in Fig 1 . Semen was placed in four tubes and diluted at $400 \times 10^{6}$ sperm $/ \mathrm{mL}$ with extenders: TCF (Tris $274 \mathrm{mM}$, citric acid $90 \mathrm{mM}$, fructose $53 \mathrm{mM}$ ), two tubes with TTF-EY (TES $224 \mathrm{mM}$, Tris $85 \mathrm{mM}$, fructose $13 \mathrm{mM}$, adding $10 \%$ clarified egg yolk), and TTF-SL (TTF adding 3.5\% of soybean lecithin). Aliquots taken from each tube were placed in seven tubes. One tube served as a control, and GSH or Trolox at $0.2,1$ or $5 \mathrm{mM}$ concentrations was placed in the other six tubes. Two other aliquots were prepared by extending the semen with the commercial extender INRA96 (IMV, L'Aigle, France), without 


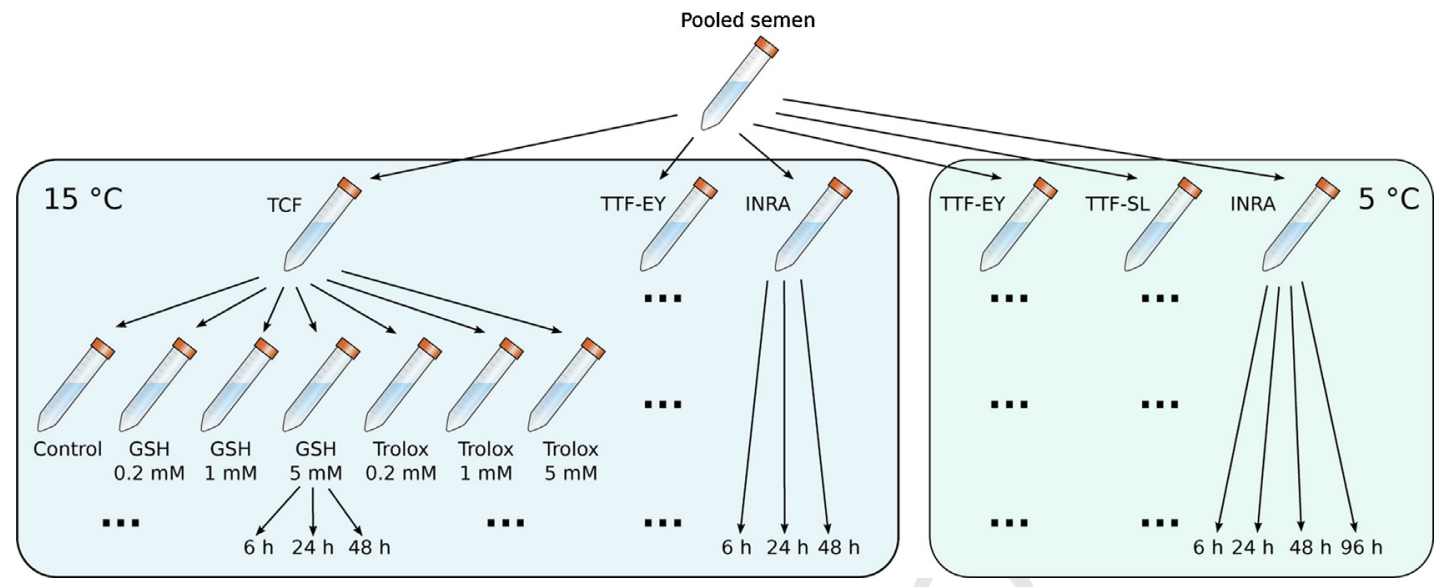

Fig. 1. Experimental design followed in this study. The pooled semen was split among four treatments (two extenders, two temperatures), and then among a control and six antioxidant treatments, and analyzed at different storage times. The full schematics is only shown for TCF with GSH 5 mM and at $15{ }^{\circ} \mathrm{C}$, the procedure being the same for the other combinations (including a sampling time at $96 \mathrm{~h}$ for samples at $5^{\circ} \mathrm{C}$ ). Part of the semen was extended in INRA96 and stored at both temperatures for comparison with the respective controls.

antioxidants. One aliquot was stored in TCF, TTF-EY or INRA96 and was stored at $15^{\circ} \mathrm{C}$, whereas the other aliquots that were stored in TTF-EY, TTF-SL or INRA96 were stored at $5^{\circ} \mathrm{C}$.

The extender $\times$ temperature combinations were evaluated so that suitability of each extender for storage at the two temperatures could be assessed. Storage with TCF is not adequate at $5{ }^{\circ} \mathrm{C}$ because of the lack of supplements to allow for sperm viability at this temperature. INRA96 was included because this experiment was conducted within an insemination program that was using this extender as the standard for storing semen, and thus INRA96 was used for comparison with the controls of TCF, TTF-EY and TTF-SL.

At 6, 24, 48 and $96 \mathrm{~h}$ of storage, samples were assessed for: motility (CASA), acrosomal status (PNA-FITC/PI), membrane permeability and mitochondrial activity (YOPRO-1/PI/Mitotracker deep red). The experiment was replicated six times in consecutive weeks.

Insemination doses for the pilot AI trial (control, GSH $1 \mathrm{mM}$ and Trolox $5 \mathrm{mM}$ ) were prepared after $6 \mathrm{~h}$ of storage from the samples stored in TCF at $15^{\circ} \mathrm{C}$, and at 6,24 and $48 \mathrm{~h}$ of storage from the samples stored in TTF-SL extender at $5{ }^{\circ} \mathrm{C}$. Only these treatments could be tested, due to the number of ewes available (few ewes could be diverted from the standard AI program).

\subsection{Semen collection and preservation}

Animals used for semen collection were five Churra breed adult males (2-5 years of age), all of proven fertility and trained for semen collection by artificial vagina. The rams were housed in an AI center (Diputación de León, Spain) complying with Spanish and European regulations. Semen collection was performed during the breeding season (autumn). Ejaculates were collected by artificial vagina (water at $40^{\circ} \mathrm{C}$ ), and the tubes were maintained in a water bath at $35^{\circ} \mathrm{C}$ during the initial evaluation of semen quality: volume, mass motility (assessed by microscopy with a warming stage at $37^{\circ} \mathrm{C}, \times 40$; score: $0-5$ ), and sperm concentration (assessed by the photocolorimetric method at
$540 \mathrm{~nm}$, using a specifically calibrated scale). Only ejaculates of acceptable quality were used (volume: $\geq 0.5 \mathrm{~mL}$; mass motility: $\geq 4$; sperm concentration: $\geq 3000 \times 10^{6}$ sperm $/ \mathrm{mL}$ ). Ejaculates from each collecting session were pooled before semen extension procedures were used.

\subsection{Motility analysis}

Motility analysis was performed using the CASA software ISAS v. 1.2 (Integrated Semen Analyser System; Proiser, Valencia, Spain). Samples were diluted in PBS $(10-20 \times 10$ cells $/ \mathrm{mL})$ and warmed to $37^{\circ} \mathrm{C}$ on a plate. Then, $5 \mu \mathrm{L}$ were placed in a Makler counting chamber $(10 \mu \mathrm{m}$ depth; Sefi Medical Instruments, Haifa, Israel) and examined at $\times 10$ (negative phase contrast) in a microscope with a warmed stage $\left(37^{\circ} \mathrm{C}\right)$. The standard parameter settings were set at 25 frames/s; 20 to $90 \mu \mathrm{m}$ for head area and VCL (velocity according to the actual path) $>10 \mu \mathrm{m} / \mathrm{s}$ to classify a sperm cell as motile. From each sample, images were saved and subsequently analyzed. The software rendered the percentage of motile sperm and standard CASA kinematic parameters: $\mathrm{VCL}(\mu \mathrm{m} / \mathrm{s}), \mathrm{VSL}$ (velocity according to the straight path, $\mu \mathrm{m} / \mathrm{s}$ ), VAP (velocity according to the smoothed path, $\mu \mathrm{m} / \mathrm{s}$ ), LIN (linearity, \%), STR (straightness, $\%$ ), WOB (wobble, \%), ALH (amplitude of the lateral displacement of the sperm head, $\mu \mathrm{m}$ ) and BCF (head beat-cross frequency, $\mathrm{Hz}$ ).

\subsection{Assessment of sperm physiology by flow cytometry}

\subsubsection{Plasma membrane integrity}

Plasma membrane integrity (viability) was assessed using the SYBR-14/PI combination. Samples were prepared at $10 \mathrm{~mL}$ in PBS with $100 \mathrm{nM}$ SYBR-14 and $2.5 \mu \mathrm{g} / \mathrm{ml}$ PI. After $15 \mathrm{~min}$ at $37^{\circ} \mathrm{C}$ in the dark, samples were analyzed. Sperm were classified among: Viable (SYBR-14+/PI-), moribund (SYBR-14+/PI+) and dead (SYBR-14-/PI+). The percentage of viable sperm (VIAB) was used for further analysis. 


\section{5 \\ 2.5.2. Acrosomal integrity} used for further analysis. ysis.
The integrity of the acrosome was estimated using the lectin peanut agglutinin (PNA) combined with fluorescein isothiocyanate (FITC). Cells were prepared at $10 \mathrm{~mL}$ in PBS with $10 \mu \mathrm{g} / \mathrm{mL}$ PNA-FITC and $2.5 \mu \mathrm{g} / \mathrm{ml}$ PI. After $15 \mathrm{~min}$ at $37^{\circ} \mathrm{C}$ in the dark, samples were analyzed. Sperm were classified as: viable, acrosome-intact ( $\mathrm{PNA}-/ \mathrm{PI}_{\bar{\Lambda}}$ ); viable, acrosome-damaged ( $\left.\mathrm{PNA}+/ \mathrm{PI}_{-}\right)$; dead, acrosome-intact (PNA-/PI+); and dead, acrosome-damaged (PNA+/PI+). The percentage of sperm with a damaged acrosome (ACR) was

\subsubsection{Mitochondrial activity}

Sperm mitochondrial function was assessed using Mitotracker deep red. This dye is readily sequestered in mitochondria, and emits red fluorescence in active mitochondria (high mitochondrial membrane potential). Samples were prepared at $10 \mathrm{~mL}$ in PBS with $100 \mathrm{nM}$ Mitotracker deep red and $0.1 \mu \mathrm{M}$ YO-PRO-1. After $15 \mathrm{~min}$ at $37^{\circ} \mathrm{C}$ in the dark, samples were analyzed, assessing the proportion of viable spermatozoa with greater mitochondrial activity (YO-PRO-1-/Mitotracker+).

\subsubsection{Plasma membrane permeability}

Variations of plasma membrane permeability were assessed using the YO-PRO-1/PI combination (PI identifies YO-PRO-1+ spermatozoa with extensive membrane damage). Samples were prepared at $10 \mathrm{~mL}$ in PBS with $100 \mathrm{nM}$ YO-PRO-1 and $2.5 \mu \mathrm{g} / \mathrm{ml}$ PI. After $15 \mathrm{~min}$ at $37^{\circ} \mathrm{C}$ in the dark, samples were analyzed. Sperm were classified as: viable, normal membrane permeability (YOPRO-1-/PI-); viable, increased membrane permeability (YO-PRO-1+/PI- ); and dead (YO-PRO-1+/PI+). The percentage of "apoptotic" sperma within the viable sperm (YO-PRO-1+ within $\mathrm{PI}_{-}$) category was used for further anal-

\subsubsection{Flow cytometer configuration}

Flow cytometric analyses were conducted on a FACScalibur (Becton Dickinson Immunochemistry Systems, San Jose, CA, USA). Green fluorescence from SYBR-14, YO-PRO1 and PNA-FITC was read with the FL1 photodetector (530/30BP filter). Red fluorescence from PI was read with the FL3 photodetector (670LP filter). These fluorochromes were excited using the Ar-ion blue laser ( $488 \mathrm{~nm}$ ). Mitotracker Deep Red was excited using a $633 \mathrm{~nm}$ He-Ne laser, and its red fluorescence was read with the FL4 photodetector (670/40BP filter). Fluorescence data were displayed in logarithmic mode using the Cell Quest Pro 3.1 software (BD Biosciences). Ten thousand events were collected per sample, with a flow rate of 200 cells/s, using a gate in forward and side scatter to exclude debris and aggregates from the analysis. The analysis of the flow cytometry data was conducted using Weasel v. 3.0.1 (WEHI, Melbourne, Australia).

\subsection{Insemination procedures}

Churra ewes (2-5 years old) kept at 10 farms were inseminated during the breeding season (autumn) within an AI program. A subset of the ewes were inseminated with doses extended in TCF and stored $6 \mathrm{~h}$ at $15^{\circ} \mathrm{C}$ or extended in TTF-SL and stored 6,24 or $48 \mathrm{~h}$ at $5{ }^{\circ} \mathrm{C}$, and only with Control, GSH $1 \mathrm{mM}$ and Trolox $5 \mathrm{mM}$ treatments, because of the small number of ewes available (due to the requirements of the AI campaign). Estrous induction and synchronization were conducted by applying intravaginal sponges with $40 \mathrm{mg}$ fluorogestone acetate (Chronogest; Intervet, Madrid, Spain) for 14 days. Sponges were removed and the ewes received an intramuscular injection with 500 IU eCG (Folligon1; Intervet, Madrid, Spain). Vaginal AI was conducted by four experienced technicians at $55 \pm 1 \mathrm{~h}$ after the removal of the sponges. The semen $\left(300 \times 10^{6}\right.$ sperm) was deposited as deep as possible. Pregnancy was diagnosed by ultrasonic assessments at 35 to 38 day after insemination. Ewes lambing as a result of AI were determined according to the births that occurred between 137 and 154 days post-insemination.

\subsection{Statistical analysis}

Data were analyzed with the R statistical environment ( $R$ Core Team, 2014). The linear mixed-effects model was used to analyze the effects of storage temperature, storage time, extender and antioxidant supplementation (fixed effects in the different models tested), using the replicate as the grouping factor in the random part of the models. Results are reported as the mean \pm SEM unless otherwise stated. Fertility data were analyzed by using logistic regression. Because farm, inseminator and ram could act as confounding factors, this was taken into account in the model.

\section{Results}

\subsection{Effects of storage temperature and extender}

The effects of temperature were established by analyzing a full model with a subset of the data (only controls - no antioxidants added $_{-}$, extenders INRA96 and TTF-EY and up to $48 \mathrm{~h}$ ). No interactions were detected, and, therefore, factors were studied as main effects (Table 1). Storage at $15^{\circ} \mathrm{C}$ yielded greater quality sperm cells than when storing at $5{ }^{\circ} \mathrm{C}$ (significant differences for total motility, progressive motility, viability and acrosomal damage). Semen quality steadily decreased with storage time (less than $10 \%$ on the average for motility, viability and acrosomal integrity).

For studying the effects of extender and time, data from 5 and $15^{\circ} \mathrm{C}$ were analyzed separately. CASA parameters (Fig 2 ) decreased with storage time. At $15^{\circ} \mathrm{C}$, total motility (Fig $2 \mathrm{a})$ was less in TCF $(P<0.05$ overall), but no differences were detected with storage at $5^{\circ} \mathrm{C}$ between the extenders (Fig 2 a). Progressive motility was greater when INRA96 was used as the extender for shorter storage times at both temperatures ( $\mathrm{Fig}, 2 \mathrm{c}$ and $\mathrm{d}$ ), but these results were affected by storage time to a greater extent than with the other extenders. With the other extenders, results for progressive motility were similar when storage occurred for $24 \mathrm{~h}$ at $15^{\circ} \mathrm{C}$ and $48 \mathrm{~h}$ at $5^{\circ} \mathrm{C}$. When storage was for $96 \mathrm{~h}$ at $5^{\circ} \mathrm{C}$, values when TTF-SL was used as the extender were slightly greater with an overall progressive motility of $9.8 \pm 1.6 \%$. The analysis of viability at $15^{\circ} \mathrm{C}$ indicated there was an important interaction between storage time and extender, 
Table 1

Effects of temperature and storage time on semen quality (no antioxidant added; storage up to $48 \mathrm{~h})^{\mathrm{a}} \wedge$

\begin{tabular}{|c|c|c|c|c|c|c|c|}
\hline & \multicolumn{3}{|c|}{ Temperature } & \multicolumn{4}{|l|}{ Time } \\
\hline & $5^{\circ} \mathrm{C}$ & $15^{\circ} \mathrm{C}$ & Effect & $6 \mathrm{~h}$ & $24 \mathrm{~h}$ & $48 \mathrm{~h}$ & Effect \\
\hline MOT (\%) & $75.0 \pm 0.7$ & $83.5 \pm 0.7$ & $P<0.001$ & $82.8 \pm 0.7$ & $79.2 \pm 0.8$ & $75.7 \pm 0.8$ & $P<0.001$ \\
\hline PROG (\%) & $26 \pm 0.8$ & $41.5 \pm 1.1$ & $P<0.001$ & $35.7 \pm 1.5$ & $34.6 \pm 0.9$ & $31 \pm 1.7$ & $P<0.001$ \\
\hline VIAB (\%) & $69.6 \pm 0.8$ & $84.4 \pm 0.7$ & $P<0.001$ & $79.2 \pm 0.5$ & $77.1 \pm 0.4$ & $75 \pm 0.5$ & $P=0.012$ \\
\hline ACR (\%) & $8.8 \pm 0.3$ & $6.3 \pm 0.3$ & $P<0.001$ & $6.7 \pm 0.1$ & $7.7 \pm 0.1$ & $8.4 \pm 0.2$ & $P=0.044$ \\
\hline APOP ratio (\%) & $2.9 \pm 0.2$ & $2.7 \pm 0.2$ & $P=0.607$ & $2.5 \pm 0.2$ & $3 \pm 0.3$ & $2.9 \pm 0.2$ & $P=0.012$ \\
\hline MITO (\%) & $56.6 \pm 1.4$ & $65.6 \pm 1.5$ & $P=0.587$ & $67.8 \pm 1.2$ & $64.8 \pm 1$ & $52.2 \pm 1.5$ & $P=0.005$ \\
\hline
\end{tabular}

MOT: total motility; PROG: progressive motility; VCL: curvilinear velocity; VIAB: viability (SYBR-14+/PI-); ACR: damaged acrosomes (PNA-FITC+); APOP ratio: proportion of "apoptotic" spermatozoa within the viable population (YO-PRO-1/PI); MITO: proportion of spermatozoa with active mitochondria (Mitotracker deep red+).

a Semen quality was greater when stored at $15^{\circ} \mathrm{C}$ overall, and decreased steadily with storage time; no interactions were detected, therefore, results are provided as main effects

(a)

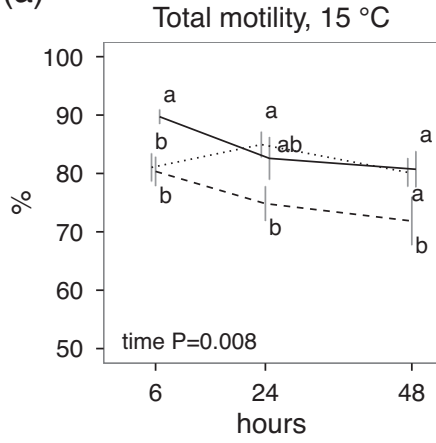

(c)

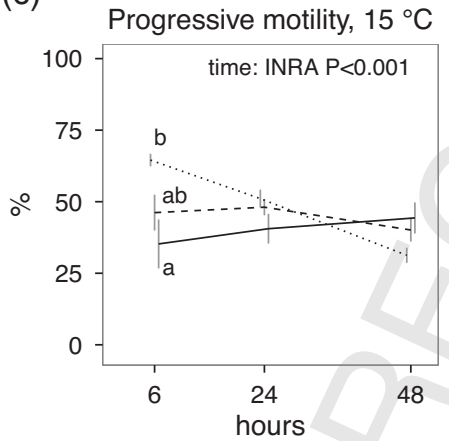

(e)

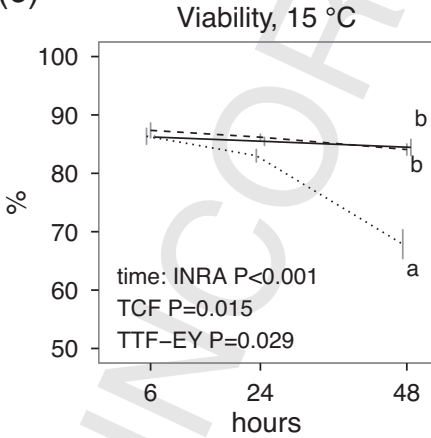

(b)

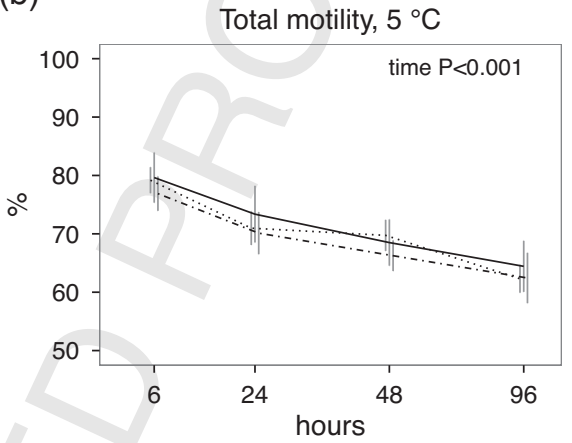

(d)

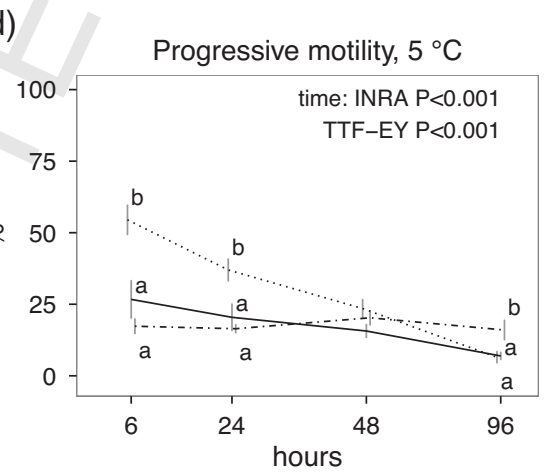

(f)

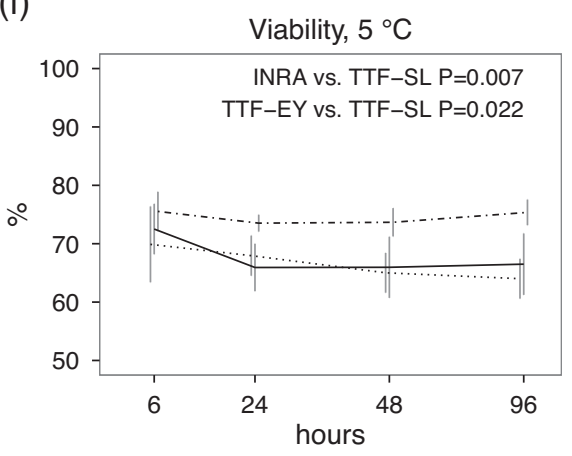

TCF
- TTF-EY - . - . TTF-SL

Fig. 2. Results for motility and viability in the first analysis (effects of temperature, extender and storage time, only controls). INRA96 and TTF-EY were used at both temperatures, whereas TCF was only used at $15^{\circ} \mathrm{C}$ and TTF-SL was only used at $5{ }^{\circ} \mathrm{C}$. Storing the samples at $5{ }^{\circ} \mathrm{C}$ yielded a lower sperm quality overall. When the interaction between extender and storage time was significant, letters show significant differences between extenders within each time, and insets show the effect of time for each extender (if $P<0.05$ ). If no interaction was detected, insets show results for main effects when significant. 
(a)

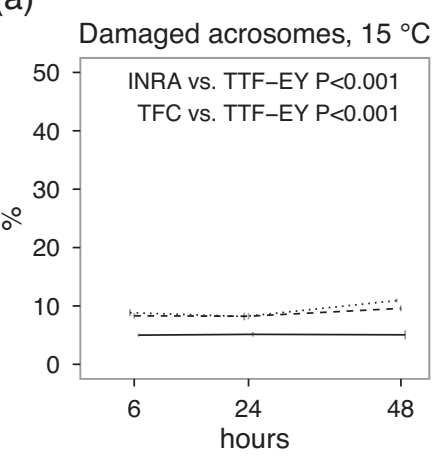

(c)

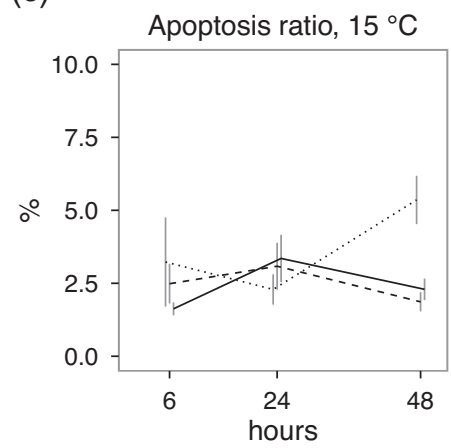

(e)

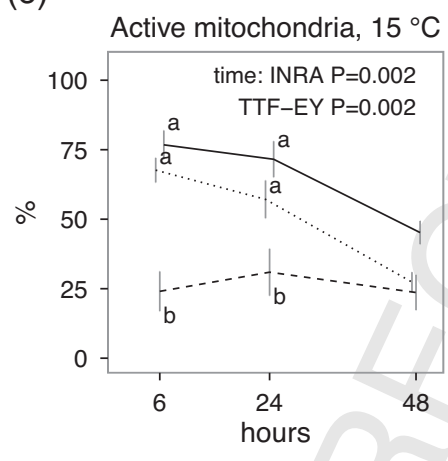

Extender:

INRA96 (b)

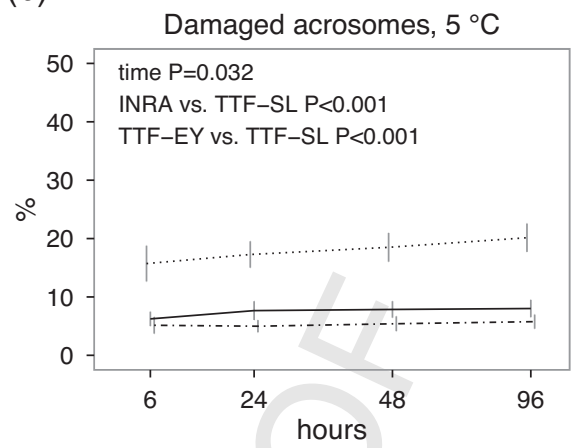

(d)

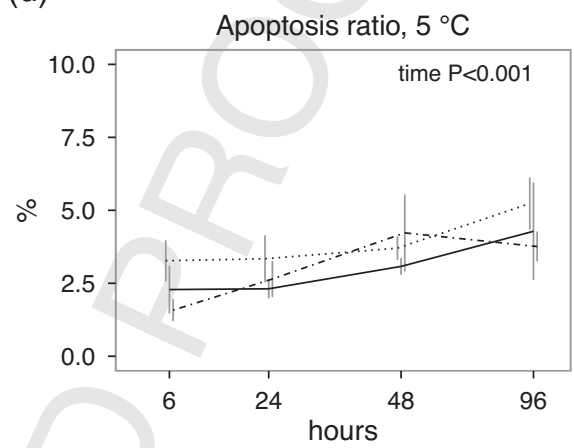

(f)

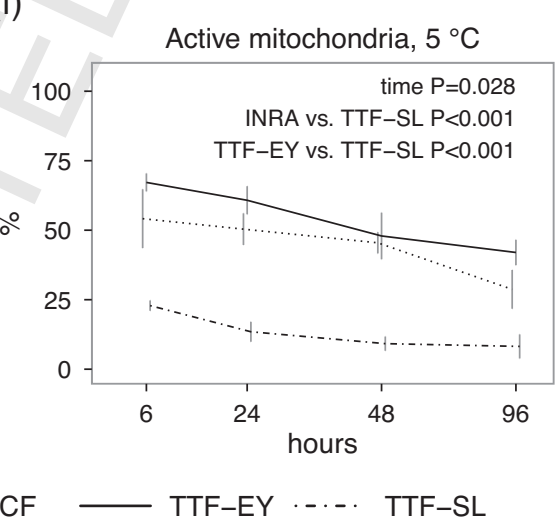

Fig. 3. Results for acrosomal status, "apoptotic" ratio and mitochondrial activity in the first analysis (continued from Fig 2 ). Storing the samples at $5{ }^{\circ} \mathrm{C}$ yielded a lower sperm quality overall, whereas storage time lowered sperm quality, although in most cases the variables changed slowly. When the interaction between extender and storage time was significant, letters show significant differences between extenders within each time, and insets show the effect of time for each extender (if $P<0.05$ ). If no interaction was detected, insets show results for main effects when significant.

due to INRA96 values decreasing at a greater rate than with the other extenders (Fig, 2e). This resulted in an important difference at $48 \mathrm{~h}$ between INRA96 (67.9 $\pm 2.6 \%)$ and the other extenders $(84.3 \pm 0.7 \% ; P<0.001)$. When storage was at $5{ }^{\circ} \mathrm{C}$, an effect of time was not detected with use of TTF-SL resulting in a greater viability ( $F i g, 2 f)$. The proportion of damaged acrosomes was less when TTF-EY was used as an extender and storage was at $15^{\circ} \mathrm{C}$ (no effect of time, Fig $3 \mathrm{a}$ ) and greater when INRA96 was used as the extender and storage was at $5{ }^{\circ} \mathrm{C}\left(\mathrm{Fig}_{\Lambda} 3 \mathrm{~b}\right)$, with use of TTF-SL resulting in lesser values. The proportion of sperm with apoptotic features was minimal in all cases (Fig $3 \mathrm{c}$ and $\mathrm{d}$ ), not being affected by the type of extender and increasing slightly with time when semen storage was at $5{ }^{\circ} \mathrm{C}$. In contrast, the proportion of sperm with active mitochondria was noticeably less with TCF as the extender when semen was stored at $15^{\circ} \mathrm{C}(\mathrm{Fig}, 3 \mathrm{e})$ and with TTF-SL as the extender when storage was at $5^{\circ} \mathrm{C}$ ( $\left.\mathrm{Fig}_{\wedge} 3 \mathrm{f}\right)$.

\subsection{Effects of antioxidants on $15^{\circ} \mathrm{C}$ storage}

The effects of the antioxidants, extenders and storage time were analyzed using a full model considering all interactions, focusing especially on those interactions involving the antioxidant treatments. Table 2 shows a summary of the results, with between-extender and 
between-treatment differences (whenever interactions between the extender and the antioxidant treatment were significant). There were no interactions occurred between treatment and time-of-storage, therefore, this information is not included in the presentation of results (additional information in Supplementary material, Fig $\mathrm{S} 1$ ).

Analyses of total motility, viability and acrosomal status indicated there were significant interactions between the extender and the antioxidant treatments, although these interactions were different for each variable. Total motility was greater when TTF-EY was used as the extender as compared to when TCF was the extender, but differences were greater in the samples supplemented with $5 \mathrm{mM}$ GSH and Trolox, because with these treatments there was a further decrease in motility in samples stored in TCF (effects $P<0.05$ compared with the control). This effect was not detected with use of TTF-EY as the extender (overall motility of $83.7 \pm 0.8 \%$ ). Viability of sperm was similar when the two extenders $(85.2 \pm 0.2 \%)$ were used with a significant difference only when GSH was used at $0.2 \mathrm{mM}$ concentration. However, inclusion of Trolox significantly decreased the sperm viability with use of TCF as the extender, but only by $2 \%$ (overall for the three concentrations). Acrosomal damage was greater with the use of TCF for all treatments, with inclusion of Trolox at the $5 \mathrm{mM}$ concentration resulting in an increased acrosomal damage as compared with the control, whereas with TTF-EY this effect was noted at all GSH concentrations and with Trolox at $5 \mathrm{mM}$. However, the effects due to the antioxidant treatments were minimal (on average, about $1 \%)$.

Progressive motility and the apoptosis ratio were not affected by the antioxidant treatment or by its interaction with the extender. Mitochondrial activity was considerably greater with TTF-EY (no interactions, Table 2).

\subsection{Effect of antioxidants on $5^{\circ} \mathrm{C}$ storage}

Results obtained in the $5^{\circ} \mathrm{C}$ experiment were analyzed in the same manner as described previously (summary Table 3, with additional information in the Supplementary material, Fig, S2). Interactions were only detected for acrosomal damage and mitochondrial status. Acrosomal damage was greater when TTF-EY was used as the extender in all cases, but average values were mostly less than $10 \%$. The antioxidant supplementation had an effect with both extenders, but effects were different with the two extenders. Inclusion of GSH at all concentrations increased the proportion of sperm with acrosomal damage (respect to the control) when the extender was TTF-EY, but these treatments decreased acrosome damage when the extender was TTF-SL. The supplementation with Trolox at $0.2 \mathrm{mM}$ slightly decreased acrosomal damage when the extender was TTF-SL. Mitochondrial activity was dramatically decreased when the extender was TTFSL compared with TTF-EY. All the antioxidant treatments improved mitochondrial status with the TTF-SL extender, especially at $5 \mathrm{mM}$. Supplementation of the extender with GSH at $5 \mathrm{mM}$ increased the proportion of sperm with active mitochondria when TTF-EY was used as the extender.

For the rest of the variables, no interactions were detected. Total sperm motility was greater when TTF-EY was used as the extender, whereas viability was greater with the TTF-SL extender. Progressive motility and the apoptotic ratio were not affected, by the antioxidant treatment or by the extender.

\subsection{Fertility trials}

During the insemination program, a total of 309 ewes were included in the pilot fertility trial. There were small differences between treatments (Table 4), with no

Table 2

Interactions of the extenders and the antioxidant treatments and their effects on semen stored at $15^{\circ} \mathrm{C}$ (no interactions with storage time). Mitochondrial status was not affected by the antioxidant treatment and, therefore, effect of the extender was assessed as a main effect. Progressivity and the apoptotic ratio were not affected by neither factor.

\begin{tabular}{|c|c|c|c|c|c|c|c|c|}
\hline Extender & Antiox. & Conc. & MOT (\%) & PROG (\%) & VIAB (\%) & ACR (\%) & APOP ratio (\%) & MITO (\%) \\
\hline \multirow[t]{7}{*}{ TCF } & Control & & $75.7 \pm 1.9$ & $44.8 \pm 3.2$ & $85.8 \pm 0.3$ & $8.7 \pm 0.3$ & $2.4 \pm 0.2$ & $26 \pm 3.5$ \\
\hline & \multirow{3}{*}{$\mathrm{GSH}$} & 0.2 & $75.2 \pm 2.5$ & $46.9 \pm 2.9$ & $86.6 \pm 0.3$ & $8.4 \pm 0.3$ & $2.2 \pm 0.3$ & $24.4 \pm 4.7$ \\
\hline & & 1 & $74.1 \pm 2.1$ & $46.2 \pm 2.5$ & $86.4 \pm 0.5$ & $8.2 \pm 0.2$ & $1.9 \pm 0.2$ & $23.1 \pm 3.7$ \\
\hline & & & $68.3 \pm 2.6^{*}$ & $43.7 \pm 2.9$ & $85.8 \pm 0.6$ & $8.3 \pm 0.2$ & $1.7 \pm 0.2$ & $22.4 \pm 3.5$ \\
\hline & \multirow{3}{*}{$\wedge^{G}$ Trolox } & & $60.4 \pm 2^{* * *}$ & $34.8 \pm 2.9$ & $83.4 \pm 0.8^{* * *}$ & $9 \pm 0.3$ & $3.2 \pm 0.3$ & $25.8 \pm 3.2$ \\
\hline & & & $67.5 \pm 2.6^{*}$ & $39 \pm 3.4$ & $84.2 \pm 0.5^{* *}$ & $8.9 \pm 0.3$ & $2.6 \pm 0.3$ & $25.5 \pm 2.7$ \\
\hline & & & $65.5 \pm 2.4^{* * *}$ & $35.7 \pm 3.2$ & $83.8 \pm 0.5^{* * *}$ & $9.8 \pm 0.3^{* *}$ & $2.6 \pm 0.4$ & $19.6 \pm 3.1$ \\
\hline \multirow[t]{7}{*}{ TTF-EY } & Control & & $84.3 \pm 1.8$ & $40 \pm 3.2$ & $85.3 \pm 0.4$ & $5.1 \pm 0.2$ & $2.4 \pm 0.4$ & $63.3 \pm 4.1$ \\
\hline & \multirow{3}{*}{$\mathrm{GSH}$} & 0.2 & $82.5 \pm 1.2$ & $37.3 \pm 3$ & $84.5 \pm 0.6$ & $6.1 \pm 0.3^{* * *}$ & $3.4 \pm 0.6$ & $64.7 \pm 3.5$ \\
\hline & & & $84 \pm 1.4$ & $42.2 \pm 2.8$ & $84.7 \pm 0.9$ & $6.1 \pm 0.3^{* * *}$ & $2.2 \pm 0.4$ & $67.3 \pm 3.6$ \\
\hline & & & $83.6 \pm 1.4$ & $44 \pm 2.3$ & $86 \pm 0.4$ & $7 \pm 0.2^{* * *}$ & $2.5 \pm 0.4$ & $69 \pm 2.9$ \\
\hline & \multirow{3}{*}{$\mathrm{G}^{\mathrm{T} \text { Trolox }}$} & & $84 \pm 1.4$ & $40.2 \pm 2.8$ & $84.9 \pm 0.8$ & $5.4 \pm 0.2$ & $2.8 \pm 0.7$ & $68.6 \pm 3.1$ \\
\hline & & & $84 \pm 1.7$ & $40.7 \pm 2.9$ & $85.6 \pm 0.6$ & $5.5 \pm 0.2$ & $2.7 \pm 0.3$ & $70 \pm 2.6$ \\
\hline & & & $83.5 \pm 1.6$ & $37.8 \pm 2.7$ & $85.4 \pm 0.6$ & $6 \pm 0.2^{* *}$ & $2.1 \pm 0.3$ & $73.5 \pm 2.7$ \\
\hline
\end{tabular}

MOT: total motility; PROG: progressive motility; VCL: curvilinear velocity; VIAB: viability (SYBR-14+/PI-); ACR: damaged acrosomes (PNA-FITC+); APOP ratio: proportion of "apoptotic" spermatozoa within the viable population (YO-PRO-1+ within PI-); MITO: proportion of spermatozoa with active mitochondria (Mitotracker deep red+).

Letters indicate differences between extenders within each antioxidant treatment (except for MITO, where capital letters indicate differences as a main effect, irrespective of the treatment); asterisks indicate effects of the antioxidant treatment, respect to the control, within each extender: $\wedge^{*}<0.05$, ** $P<0.01 ;{ }^{* * *} P<0.001$. 


\section{Table 3}

Interactions of the extenders and the antioxidant treatments and their effects on semen stored at $5^{\circ} \mathrm{C}$ (no interactions with storage time). Total motility and viability were not affected by the antioxidant treatment, and the effect of the extender was assessed as a main effect. Progressivity and the apoptotic ratio were not affected by neither factor.

\begin{tabular}{|c|c|c|c|c|c|c|c|c|}
\hline Extender & Antiox. & Conc. & MOT (\%) & PROG (\%) & VIAB (\%) & $\operatorname{ACR}(\%)$ & APOP ratio (\%) & MITO (\%) \\
\hline \multirow[t]{7}{*}{ TTF-EY } & Control & & $71.5 \pm 1.3$ & $17.4 \pm 1.6$ & $67.5 \pm 1.5$ & $7.4 \pm 0.2$ & $3.1 \pm 0.4$ & $53.6 \pm 2.3$ \\
\hline & GSH & 0.2 & $73.9 \pm 2.3$ & $20.7 \pm 1.9$ & $68.7 \pm 2$ & $7.8 \pm 0.3^{* *}$ & $3 \pm 0.4$ & $57.4 \pm 2.2$ \\
\hline & & 1 & $73.4 \pm 1.6$ & $21.9 \pm 1.6$ & $67.3 \pm 1.9$ & $8.8 \pm 0.4^{* * *}$ & $2.1 \pm 0.3$ & $55 \pm 2.5$ \\
\hline & & $\hat{5}$ & $72.3 \pm 1.4$ & $21.4 \pm 1.6$ & $71.8 \pm 1$ & $10.4 \pm 0.8^{* * *}$ & $2.3 \pm 0.3$ & $59.5 \pm 2^{* *}$ \\
\hline & Trolox & 0.2 & $73.8 \pm 1.7$ & $23.9 \pm 2.1$ & $70.8 \pm 1.9$ & $7.1 \pm 0.2$ & $3.2 \pm 0.4$ & $58.9 \pm 2.3$ \\
\hline & & 1 & $72.5 \pm 1.8$ & $22.5 \pm 2.1$ & $71.1 \pm 1$ & $7.5 \pm 0.2$ & $3.4 \pm 0.7$ & $54.5 \pm 2.4$ \\
\hline & & $\hat{5}$ & $73.3 \pm 1.3$ & $22.2 \pm 1.9$ & $69.1 \pm 1.4$ & $7.5 \pm 0.2$ & $3.7 \pm 0.4$ & $49.6 \pm 2.1$ \\
\hline \multirow[t]{7}{*}{ TTF-SL } & Control & & $68.9 \pm 1.6$ & $17.5 \pm 2$ & $74.5 \pm 1.7$ & $5.3 \pm 0.3$ & $3.1 \pm 0.4$ & $13 \pm 2$ \\
\hline & $\mathrm{GSH}$ & 0.2 & $70 \pm 2.1$ & $18.2 \pm 2.3$ & $75.5 \pm 1.8$ & $4.8 \pm 0.3^{* *}$ & $3.4 \pm 0.4$ & $16.9 \pm 2.1^{*}$ \\
\hline & & 1 & $67.4 \pm 1.7$ & $18.4 \pm 1.6$ & $76.1 \pm 2.2$ & $4.5 \pm 0.3^{* * *}$ & $3 \pm 0.4$ & $18.7 \pm 3^{* *}$ \\
\hline & & $\hat{5}$ & $67.2 \pm 1.6$ & $18.7 \pm 1.3$ & $76 \pm 1.2$ & $4.6 \pm 0.2^{* * *}$ & $2.5 \pm 0.2$ & $21.3 \pm 2.5^{* * *}$ \\
\hline & Trolox & 0.2 & $68.6 \pm 1.9$ & $18.5 \pm 1.9$ & $75.5 \pm 1$ & $4.9 \pm 0.2^{*}$ & $4.1 \pm 0.4$ & $18.1 \pm 1.9^{*}$ \\
\hline & & 1 & $67.7 \pm 2$ & $21.6 \pm 1.8$ & $75.5 \pm 1.1$ & $5.1 \pm 0.2$ & $3.2 \pm 0.3$ & $17.6 \pm 2.1^{*}$ \\
\hline & & 5 & $72.9 \pm 1.3$ & $21.5 \pm 1.7$ & $80.4 \pm 1.1$ & $5.2 \pm 0.2$ & $3.1 \pm 0.3$ & $23.4 \pm 2.2^{* * *}$ \\
\hline
\end{tabular}

MOT: total motility; PROG: progressive motility; VCL: curvilinear velocity; VIAB: viability (SYBR-14+/PI-); ACR: damaged acrosomes (PNA-FITC+); APOP ratio: proportion of "apoptotic" spermatozoa within the viable population (YO-PRO-1+ within PI-); MITO: proportion of spermatozoa with active mitochondria (Mitotracker deep red+).

Letters indicate differences between extenders within each antioxidant treatment (except for MOT and VIAB, where capital letters indicate differences as a main effect, irrespective of the treatment); asterisks indicate effects of the antioxidant treatment, respect to the control, within each extender: $\wedge^{*}<0.05$, ${ }^{* *} P<0.01 ;{ }^{* * *} P<0.001$.

significant effects of the antioxidants. Some fertility trends, as a result of treatment, were detected. Use of control samples stored at $15^{\circ} \mathrm{C}$ for $6 \mathrm{~h}$ for AI resulted in a $21 \%$ lambing rate, whereas use of samples supplemented with GSH at the $1 \mathrm{mM}$ concentration resulted in a $37 \%$ lambing rate $(P=0.099)$. Results of $\mathrm{AI}$ with samples stored at $5{ }^{\circ} \mathrm{C}$, were similar between treatments when storage was for $6 \mathrm{~h}$. However, AI with samples that were supplemented with GSH at the $1 \mathrm{mM}$ concentration and stored for $24 \mathrm{~h}$ resulted in a trend $(P=0.064)$ of increased lambing rate. Fertility as a result of AI when control samples were used was reduced when the semen storage was for $24 \mathrm{~h}$ compared with $6 \mathrm{~h}$ ( $28 \%$ to $4 \%, P<0.032$ ), however, there was no respective decrease with antioxidant treatment supplementations.

\section{Discussion}

Refrigerated storage of ram semen allows extending its useful life, but it does not eliminate the decrease of semen quality with time, which results in fertility loss. One of the consequences of semen storage is the oxidative stress produced not only by the production of free radicals and the accumulation of waste substances, but also by a decrease of the antioxidant capacity of the sample (Donnelly et al., 2000). Moreover, the sperm plasma membrane is especially susceptible to lipid peroxidation, because of the great proportion of polyunsaturated fatty acids (Storey, 2008). Thus, in the present study the protective effects of Trolox and reduced glutathione $(\mathrm{GSH})$ in the millimolar range were evaluated. It is interesting to note that the efficiency of these antioxidants was affected by other components of the medium, resulting in the interactions detected between the extender and the antioxidant treatment at both temperatures. This outcome is to be expected, because supplements such as egg yolk and lecithin not only have antioxidant activity (Alvarez-Rodríguez et al., 2013), but also modulate the activity of antioxidants by interacting with the plasma membrane or with other cell components.

Trolox is a very interesting antioxidant, because it is a derivative of vitamin $\mathrm{E}$ ( $\alpha$-tocopherol) with a greater aqueous solubility, allowing for use in greater concentrations. In previous studies, Trolox had a high efficiency as a radical scavenger even for relatively long incubations at physiological temperatures (Domínguez-Rebolledo et al., 2009, 2010), and has been an important supplement for ram semen cryopreservation with positive results (Maia et al., 2010, and unpublished data). However, adding this antioxidant to samples stored at $15^{\circ} \mathrm{C}$ in TCF in the present study resulted in decreased sperm motility and viability and increased acrosomal damage when used at $5 \mathrm{mM}$ (even

Table 4

Results of the fertility trials, showing absolute numbers for total inseminations and lambed ewes, and the proportion of lambing. Ewes inseminated at $48 \mathrm{~h}$ with semen stored at $5{ }^{\circ} \mathrm{C}$ did not result in lambing (12 ewes in each group). The dots indicate non-significant effects of GSH with $P<0.1$.

\begin{tabular}{|c|c|c|c|c|c|}
\hline \multirow[t]{2}{*}{ Temperature } & \multirow{2}{*}{ Treatment } & \multicolumn{2}{|l|}{$6 \mathrm{~h}$} & \multicolumn{2}{|l|}{$24 \mathrm{~h}$} \\
\hline & & Inseminated & Lambed & Inseminated & Lambed \\
\hline \multirow[t]{3}{*}{$15^{\circ} \mathrm{C}$} & Control & 38 & $8(21 \%)$ & & \\
\hline & $\mathrm{GSH} 1 \mathrm{mM}$ & 38 & $14(37 \%)^{\bullet}$ & & \\
\hline & Trolox $5 \mathrm{mM}$ & 35 & 10 (29\%) & & \\
\hline \multirow[t]{3}{*}{$5^{\circ} \mathrm{C}$} & Control & 25 & $7(28 \%)$ & 25 & $1(4 \%)$ \\
\hline & GSH $1 \mathrm{mM}$ & 25 & $5(20 \%)$ & 24 & $6(25 \%)^{\bullet}$ \\
\hline & Trolox $5 \mathrm{mM}$ & 24 & $7(29 \%)$ & 25 & $5(20 \%)$ \\
\hline
\end{tabular}


in TTF-EY) concentrations. Interestingly, these effects were not observed at $5^{\circ} \mathrm{C}$. Is it possible that, in absence of other supplements, Trolox could interfere with pathways using free radicals as second messengers, causing this loss of sperm viability. This negative effect has been observed when evaluating other antioxidants in ram semen (MataCampuzano et al., 2012a), or with Trolox for cryopreserving deer sperm (Anel-López et al., 2012; Fernández-Santos et al., 2007). Foote et al. (2002) noted that the toxic effects of the antioxidants TEMPO and TEMPOL in bull semen were more evident with a milk-based extender than an egg yolkbased extender. Therefore, Trolox might have a toxic effect on refrigerated ram semen, which would be negated by use of lipid supplements such as egg yolk or lecithin. Despite these in vitro results, use of Trolox as a supplement to the semen extender did not decrease fertility in the present study. There was, however, no evidence for a potential positive effect.

Supplementation of the extender with GSH resulted in few effects. Supplementation with GSH increased the proportion of damaged acrosomes when TTF-EY was the extender, whereas its use decreased the proportion of damaged acrosomes when TTF-SL was used as the extender. This effect was minimal and might have resulted from an underlying interaction between the extender and the antioxidant that deserves further research. The acrosomal integrity depends on many different cellular structures and pathways (the integrity of the plasma and acrosomal membranes, the cytoskeleton between these two structures, calcium concentrations, channel and receptordependent pathways, etc.; Benoff, 1999; Tapia et al., 2012), and therefore, changes at one of these sites could impact the proportion of sperm having acrosomal damage. In the present study, there was not substantial evidence of an effect on fertility, however, there was some indication of an advantage when there was less GSH supplementation. The trends for acrosome damage with use of GSH have no practical value, but these results could be useful for future studies including larger fertility trials. Nevertheless, the GSH treatments prevented the decrease of fertility observed with the control samples stored at $5^{\circ} \mathrm{C}$. From previous research, an increase in fertility has been reported when using antioxidants. For example, Maxwell and Stojanov (1996) found that pregnancy rates, after intrauterine insemination, were greater when semen was stored for 7 and 14 days that was supplemented with superoxide dismutase and catalase ( $41 \%$ vs. $16 \%$ ). More recently, Mara et al. (2005) found an improvement in fertility and blastocyst rate development in an in vitro experiment, when sperm were stored at $15^{\circ} \mathrm{C}$ in presence of the antioxidant TEMPOL, and Casao et al. (2010) reported an increase in the cleavage rate after treating sperm with small amounts of melatonin. In addition to the effects of antioxidants, there was an overall greater quality in the samples of the present study that were maintained at $15^{\circ} \mathrm{C}$. Although there are many reports on the quality of ram semen stored either at 15 or $5^{\circ} \mathrm{C}$ (Salamon and Maxwell, 2000), only a few of these previous studies directly compared both temperatures under similar conditions (Colas et al., 1968; Hollinshead et al., 2004; O'Hara et al., 2010). These direct-comparison studies are necessary to fully understand differences between these two temperatures while controlling for confounding variables, and thus this was one of the objectives of the present study. Although liquid storage at lesser temperatures could extend the useful life of sperm by reducing metabolic rate, these conditions might lead to increased sperm cell stress. Even if the protocols and extenders are designed to minimize cold shock, changes in membrane fluidity and other undesirable effects are expected. These effects could explain the lesser motility and viability observed in the present experiment in the samples stored at $5{ }^{\circ} \mathrm{C}$ up to $48 \mathrm{~h}$. Other studies have detected little difference and even an advantage for storage of semen at $5^{\circ} \mathrm{C}$ for similar time periods as those in the present study. For example, O'Hara et al. (2010) provided evidence that storage at $15^{\circ} \mathrm{C}$ resulted in decreases in sperm motility at a more rapid rate than storage at $5^{\circ} \mathrm{C}$, with noticeable differences as early as $24 \mathrm{~h}$ of storage. However, the extender has an important role in maintaining sperm quality over the time periods sperm are stored. Indeed, in previous studies when INRA96 was used, as was the case in the present study, the differences in sperm quality for the different temperatures were much less at $48 \mathrm{~h}$ of storage. Colas et al. (1968) also detected small differences when comparing sperm quality after 2 and $14 \mathrm{~h}$ (milk-catalase extender) of storage, whereas Hollinshead et al. (2004) stored the samples up to 24 hand found no differences.

Regarding fertility at both storage temperatures, IVF results of O'Hara et al. (2010) suggest that fertilizing capacity of sperm when semen is stored at $15^{\circ} \mathrm{C}$ was greater at 6 and at $24 \mathrm{~h}$ of storage as compared with storage at $5^{\circ} \mathrm{C}$. Of course, the storage of semen at $5^{\circ} \mathrm{C}$ is clearly advantageous if use of the semen is delayed for several days. In the present study, samples were stored at $15^{\circ} \mathrm{C}$ only for $48 \mathrm{~h}$, not allowing for direct comparisons of results, but the acceptable results of samples stored at $5{ }^{\circ} \mathrm{C}$ for $96 \mathrm{~h}$ are consistent with results from previous research where storage occurred for $72 \mathrm{~h}$ or longer. Thus, O'Hara et al. (2010) obtained acceptable blastocyst rates when using semen that had been stored for $72 \mathrm{~h}$ (95\% C.I.: $11.3-34.4 \%$ with INRA96, compared with only $1 \%$ of the oocytes fertilized with semen stored at $15^{\circ} \mathrm{C}$ ). Factors influencing fertility in the field are more difficult to control than in an IVF setting, and, in the present AI trial, inseminating with semen stored for $48 \mathrm{~h}$ at $5{ }^{\circ} \mathrm{C}$ resulted in no lambings. Nevertheless, it is possible to obtain acceptable fertility with semen stored for several days at $5{ }^{\circ} \mathrm{C}$, as reported in previous studies (Maxwell and Salamon, 1993).

The extender is another important variable when designing a protocol for storing ram semen. In the present experiment, the extender clearly affected sperm quality. Lipid or protein supplements can help maintain sperm quality, possibly by interacting with the plasma membrane and by modulating the activity of seminal plasma proteins (Beirão et al., 2012; Bergeron and Manjunath, 2006), or even interacting at other cell organelles (Mendoza et al., 2013). When semen was stored at $15^{\circ} \mathrm{C}$ in the present study, INRA96 (supplemented with milk micellar proteins) and TTF-EY (supplemented with egg yolk) extenders were more efficient for maintaining sperm motility, especially when storage was for longer times. At least part of the 
effect of these extenders seems to be mediated by membrane stabilization because the viability of sperm with use of TCF extender clearly decreased at $48 \mathrm{~h}$ of storage, which was not observed when the other extenders were used. However, the protective effects of these extenders could be mediated at other levels, given that there was maintenance of most sperm cells with active mitochondria for at least $24 \mathrm{~h}$ of storage. These differences were not as evident when semen was stored at $5^{\circ} \mathrm{C}$, possibly because only extenders with supplements were used in the present research. Interestingly, the use of the lecithin-based extender (TTFSL) improved membrane integrity and reduced acrosomal damage, whereas this same extender seemed to depress mitochondrial activity. The results with using this extender in the present study were comparable to use of the egg yolk extender in a previous study (de Paz et al., 2010), and there have been positive results in several previous studies using soybean lecithin-based extenders for ram semen cryopreservation (Forouzanfar et al., 2010; Najafi et al., 2013). However, in previous research there have been indications that use of soybean lecithin might decrease mitochondrial activity in ram semen, while sperm motility and viability are sustained (Del Valle et al., 2012). In this previous research decreased mitochondrial activity was associated with a lesser post-thawing quality, especially after incubating the thawed samples, even though membrane integrity was comparable to the samples frozen with egg yolk. In this previous study, loss of mitochondrial membrane potential was associated with loss of the phospholipid cardiolipin from the mitochondrial inner membrane, indicating soybean lecithin not only exerts its effects externally, but that it can affect intracellular membranes. Even though the overall results were acceptable for sperm quality in the present study when TTF-SL was used, there should be further research to assess the impact of mitochondrial activity on fertility.

Application of antioxidants ameliorated, but did not completely reverse the depression of mitochondrial activity that occurred with use of soybean lecithin as an extender supplement. There was not a definitive doseresponse effect, but at the $5 \mathrm{mM}$ concentration there was a greater recovery of mitochondrial activity with GSH and Trolox effects being similar. Because these two antioxidants are chemically very different, it is likely that the effects could be mediated by free radical scavenging. The displacement of cardiolipin by lecithin that was described by Del Valle et al. (2012) could decrease the membrane potential because this phospholipid helps to stabilize the protein complexes and functions as a proton trap to prevent $\mathrm{pH}$ changes in the mitochondrial intermembrane space (Haines and Dencher, 2002). Without specific research it is difficult to propose a mechanism by which these antioxidants could improve mitochondrial activity. Antioxidants might reduce cardiolipin loss or allow for maintenance of the mitochondrial transmembrane potential, even with the lesser cardiolipin content.

In conclusion, the antioxidants evaluated in the present study had a small impact on sperm quality, and Trolox was detrimental to sperm quality when combined with the TCF extender. Using an extender supplemented with protein or lipids resulted in greater sperm quality during storage at $15^{\circ} \mathrm{C}$. With storage at $5^{\circ} \mathrm{C}$, the extender impacts on sperm quality were similar, except for the negative effect on mitochondrial activity that resulted from use of TTF-SL as an extender. However, supplementing the TTF-SL extender with antioxidants partially prevented the loss of mitochondrial activity. The preliminary fertility trial showed some promising effects of GSH as a semen extender additive and there needs to be further research of the type conducted in the present study with larger numbers of animals to assess potential impacts on fertility.

\section{Conflict of interest statement}

None.

\section{Acknowledgements}

The authors thank Diputación de León and ANCHE (National Association of Churra Breeders). This work has been supported by projects RZ2010-00005-0000, AGL2010-15758 (MINECO, Spain), 20130020000788 (MAGRAMA, Spain) and LE019A10-2 (Junta de Castilla y León, Spain). F. Martínez-Pastor was supported by the Ramón y Cajal program (RYC-2008-02560, Ministry of Science and Innovation, Spain).

\section{References}

Alvarez-Rodríguez, M., Alvarez, M., Anel-López, L., Martínez-Rodríguez, C., Martínez-Pastor, F., Borragan, S., Anel, L., de Paz, P., 2013. The antioxidant effects of soybean lecithin- or low-density lipoproteinbased extenders for the cryopreservation of brown-bear (Ursus arctos) spermatozoa. Reprod. Fertil. Dev 25, 1185-1193.

Anel, L., Alvarez, M., Martinez-Pastor, F., Garcia-Macias, V., Anel, E., de Paz, P., 2006. Improvement strategies in ovine artificial insemination. Reprod. Domest Anim. 41 (Suppl. 2), 30-42.

Anel-López, L., Alvarez-Rodríguez, M., García-Álvarez, O., Alvarez, M. Maroto-Morales, A., Anel, L., de Paz, P., Garde, J.J., Martínez-Pastor, F., 2012. Reduced glutathione and Trolox (vitamin E) as extender supplements in cryopreservation of red deer epididymal spermatozoa. Anim. Reprod. Sci 135, 37-46.

Beirão, J., Zilli, L., Vilella, S., Cabrita, E., Schiavone, R., Herráez, M.P., 2012. Improving sperm cryopreservation with antifreeze proteins: effect on gilthead seabream (Sparus aurata) plasma membrane lipids. Biol. Reprod 86, 59.

Benoff, S., 1999. Receptors and channels regulating acrosome reactions. Hum Fertil. (Camb.) 2, 42-55.

Bergeron, A., Manjunath, P., 2006. New insights towards understanding the mechanisms of sperm protection by egg yolk and milk. Mol Reprod. Dev. 73, 1338-1344.

Bilodeau, J.F., Blanchette, S., Gagnon, C., Sirard, M.A., 2001. Thiols prevent $\mathrm{H}_{2} \mathrm{O}_{2}$-mediated loss of sperm motility in cryopreserved bull semen. Theriogenology 56, 275-286.

Bucak, M.N., Coyan, K., Oztürk, C., Güngör, S., Omür, A.D., 2012. Methionine supplementation improves ram sperm parameters during liquid storage at $5^{\circ} \mathrm{C}$. Cryobiology 65, 335-337.

Bucak, M.N., Tuncer, P.B., Sarı̈̈zkan, S., Başpınar, N., Taşpınar, M., Coyan, K., Bilgili, A., Akalın, P.P., Büyükleblebici, S., Aydos, S., Ilgaz, S., Sunguroğlu, A., Oztuna, D., 2010. Effects of antioxidants on post-thawed bovine sperm and oxidative stress parameters: antioxidants protect DNA integrity against cryodamage. Cryobiology 61, 248-253.

Casao, A., Mendoza, N., Pérez-Pé, R., Grasa, P., Abecia, J.-A., Forcada, F., Cebrián-Pérez, J.A., Muino-Blanco, T., 2010. Melatonin prevents capacitation and apoptotic-like changes of ram spermatozoa and increases fertility rate. J. Pineal Res. 48, 39-46.

Colas, G., Dauzier, L., Courot, M., Ortavant, R., Signoret, J.-P., 1968. Résultats obtenus au cours de l'étude de quelques facteurs importants de l'insémination artificielle ovine. Ann. Zootechnol. 17, 47-57.

Contri, A., De Amicis, I., Molinari, A., Faustini, M., Gramenzi, A., Robbe, D. Carluccio, A., 2011. Effect of dietary antioxidant supplementation on fresh semen quality in stallion. Theriogenology 75, 1319-1326. 
Coyan, K., Başpınar, N., Bucak, M.N., Akalın, P.P., 2011. Effects of cysteine and ergothioneine on post-thawed merino ram sperm and biochemical parameters. Cryobiology 63, 1-6.

de Paz, P., Esteso, M.C., Alvarez, M., Mata, M., Chamorro, C.A., Anel, L., 2010. Development of extender based on soybean lecithin for its application in liquid ram semen. Theriogenology 74, 663-671.

Del Valle, I., Gómez-Durán, A., Holt, W.V., Muiño-Blanco, T., CebriánPérez, J.A., 2012. Soy lecithin interferes with mitochondrial function in frozen-thawed ram spermatozoa. J. Androl. 33, 717-725.

Deneke, S.M., 2000. Thiol-based antioxidants. Curr. Top. Cell Regul 36, 151-180.

Domínguez-Rebolledo, A.E., Fernández-Santos, M.R., Bisbal, A., RosSantaella, J.L., Ramón, M., Carmona, M., Martínez-Pastor, F., Garde, J.J., 2010. Improving the effect of incubation and oxidative stress on thawed spermatozoa from red deer by using different antioxidant treatments. Reprod. Fertil. Dev. 22, 856-870.

Domínguez-Rebolledo, A.E., Fernández-Santos, M.R., García-Álvarez, O., Maroto-Morales, A., Garde, J.J., Martínez-Pastor, F., 2009. Washing increases the susceptibility to exogenous oxidative stress in red deer spermatozoa. Theriogenology 72, 1073-1084.

Donnelly, E.T., McClure, N., Lewis, S.E., 2000. Glutathione and hypotaurine in vitro: effects on human sperm motility, DNA integrity and production of reactive oxygen species. Mutagenesis 15, 61-68.

Druart, X., Cognié, J., Baril, G., Clément, F., Dacheux, J.-L., Gatti, J.-L., 2009. In vivo imaging of in situ motility of fresh and liquid stored ram spermatozoa in the ewe genital tract. Reproduction 138, 45-53.

Emamverdi, M., Zhandi, M., Zare Shahneh, A., Sharafi, M., Akbari-Sharif, A., 2013. Optimization of ram semen cryopreservation using a chemically defined soybean lecithin-based extender. Reprod. Domest. Anim 48 , 899-904.

Faigl, V., Vass, N., Jávor, A., Kulcsár, M., Solti, L., Amiridis, G., Cseh, S., 2012. Artificial insemination of small ruminants - a review. Acta Vet Hung. $60,115-129$

Fernández-Santos, M.R., Martínez-Pastor, F., García-Macías, V., Esteso, M.C., Soler, A.J., Paz, P., Anel, L., Garde, J.J., 2007. Sperm characteristics and DNA integrity of Jberian red deer (Cervus elaphus hispanicus) epididymal spermatozoa frozen in the presence of enzymatic and nonenzymatic antioxidants. J. Androl. 28, 294-305.

Foote, R.H., Brockett, C.C., Kaproth, M.T., 2002. Motility and fertility of bull sperm in whole milk extender containing antioxidants. Anim. Reprod. Sci. 71, 13-23.

Forouzanfar, M., Sharafi, M., Hosseini, S.M., Ostadhosseini, S., Hajian, M., Hosseini, L., Abedi, P., Nili, N., Rahmani, H.R., Nasr-Esfahani, M.H., 2010. In vitro comparison of egg yolk-based and soybean lecithinbased extenders for cryopreservation of ram semen. Theriogenology $73,480-487$

Haines, T.H., Dencher, N.A., 2002. Cardiolipin: a proton trap for oxidative phosphorylation. FEBS Lett, 528, 35-39.

Hollinshead, F.K., O’Brien, J.K., Gillan, L., Meyers, M., Maxwell, W.M.C., Evans, G., 2004. Liquid storage of flow cytometrically sorted ram spermatozoa. Theriogenology 62, 587-605.

Khalifa, T., Lymberopoulos, A., Theodosiadou, E., 2013. Association of soybean-based extenders with field fertility of stored ram (Ovis aries) semen: a randomized double-blind parallel group design. Theriogenology 79, 517-527.

Maia, M.d.S., Bicudo, S.D., Sicherle, C.C., Rodello, L., Gallego, I.C.S., 2010. Lipid peroxidation and generation of hydrogen peroxide in frozenthawed ram semen cryopreserved in extenders with antioxidants. Anim. Reprod. Sci. 122, 118-123.

Mara, L., Accardo, C., Pilichi, S., Dattena, M., Chessa, F., Chessa, B., Branca, A., Cappai, P., 2005. Benefits of TEMPOL on ram semen motility and in vitro fertility: a preliminary study. Theriogenology 63, 2243-2253.

Mata-Campuzano, M., Alvarez-Rodríguez, M., Alvarez, M., Anel, L., de Paz, P., Garde, J.J., Martínez-Pastor, F., 2012a. Effect of several antioxidants on thawed ram spermatozoa submitted to $37 \lambda \mathrm{C}$ up to four hours. Reprod. Domest. Anim 47, 907-914.
Mata-Campuzano, M., Alvarez-Rodríguez, M., del Olmo, E., FernándezSantos, M.R., Garde, J.J., Martínez-Pastor, F., 2012b. Quality, oxidative markers and DNA damage (DNA) fragmentation of red deer thawed spermatozoa after incubation at $37, \mathrm{C}$ in presence of several antioxidants. Theriogenology 78, 1005-1019.

Maxwell, W.M., Salamon, S., 1993. Liquid storage of ram semen: a review. Reprod. Fertil. Dev. 5, 613-638.

Maxwell, W.M., Stojanov, T., 1996. Liquid storage of ram semen in the absence or presence of some antioxidants. Reprod. Fertil. Dev. 8, 1013-1020.

Memon, A.A., Wahid, H., Rosnina, Y., Goh, Y.M., Ebrahimi, M., Nadia, F.M., 2012. Effect of antioxidants on post thaw microscopic, oxidative stress parameter and fertility of boer goat spermatozoa in tris egg yolk glycerol extender. Anim. Reprod. Sci. 136, 55-60.

Mendoza, N., Casao, A., Pérez-Pé, R., Cebrián-Pérez, J.A., Muiño-Blanco, T., 2013. New insights into the mechanisms of ram sperm protection by seminal plasma proteins. Biol. Reprod 88, 149.

Najafi, A., Zhandi, M., Towhidi, A., Sharafi, M., Akbari Sharif, A., Khodaei Motlagh, M., Martinez-Pastor, F., 2013. Trehalose and glycerol have a dose-dependent synergistic effect on the post-thawing quality of ram semen cryopreserved in a soybean lecithin-based extender. Cryobiology $66,275-282$.

Nasiri, A.H., Towhidi, A., Zeinoaldini, S., 2012. Combined effect of DHA and $\alpha$-tocopherol supplementation during bull semen cryopreservation on sperm characteristics and fatty acid composition. Andrologia 44 (Suppl 1), 550-555.

O'Hara, L., Hanrahan, J.P., Richardson, L., Donovan, A., Fair, S., Evans, A.C.O., Lonergan, P., 2010. Effect of storage duration, storage temperature, and diluent on the viability and fertility of fresh ram sperm. Theriogenology 73, 541-549.

Palacín, I., Yániz, J.L., Fantova, E., Blasco, M.E., Quintín-Casorrán, F.J., Sevilla-Mur, E., Santolaria, P., 2012. Factors affecting fertility after cervical insemination with cooled semen in meat sheep. Anim. Reprod. Sci. 132, 139-144.

Pérez-Pé, R., Cebrián-Pérez, J.A., Muiño-Blanco, T., 2001. Semen plasma proteins prevent cold-shock membrane damage to ram spermatozoa. Theriogenology 56, 425-434.

R Core Team, 2014. R: A Language and Environment for Statistical Computing. R Foundation for Statistical Computing, Vienna, Austria.

Salamon, S., Maxwell, W.M., 2000. Storage of ram semen. Anim. Reprod. Sci. 62, 77-111.

Speight, S.M., Estienne, M.J., Harper, A.F., Crawford, R.J., Knight, J.W., Whitaker, B.D., 2012. Effects of dietary supplementation with an organic source of selenium on characteristics of semen quality and in vitro fertility in boars. J. Anim. Sci. 90, 761-770.

Storey, B.T., 2008. Mammalian sperm metabolism: oxygen and sugar, friend and foe. Int J. Dev. Biol. 52, 427-437.

Tapia, J.A., Macias-Garcia, B., Miro-Moran, A., Ortega-Ferrusola, C., Salido, G.M., Peña, F.J., Aparicio, I.M., 2012. The membrane of the mammalian spermatozoa: much more than an inert envelope. Reprod. Domest Anim. 47 (Suppl. 3), 65-75.

Tuncer, P.B., Bucak, M.N., Büyükleblebici, S., Sarıözkan, S., Yeni, D., Eken, A., Akalın, P.P., Kinet, H., Avdatek, F., Fidan, A.F., Gündoğan, M., 2010. The effect of cysteine and glutathione on sperm and oxidative stress parameters of post-thawed bull semen. Cryobiology 61, 303-307.

Vallorani, C., Spinaci, M., Bucci, D., Tamanini, C., Galeati, G., 2010. Effects of antioxidants on boar spermatozoa during sorting and storage. Anim, Reprod. Sci. 122, 58-65.

Watson, P.F., 1981. The roles of lipid and protein in the protection of ram spermatozoa at 5 degrees $C$ by egg-yolk lipoprotein. J. Reprod. Fertil. $62,483-492$

Xia, C., Xia, W., Yang, S., An, L., Li, X., Wu, Z., Zhang, J., Wang, Z., Tian, J., 2012. Effect of antioxidant supplementation on function and fertility of sex-sorted boar spermatozoa. Anim. Reprod. Sci, 136, 108-114. 